\title{
Molecular monitoring of Plasmodium falciparum resistance to artemisinin in Tanzania
} Kefas Mugittu*1,2, Blaise Genton ${ }^{1,2}$, Hassan Mshinda ${ }^{1}$ and Hans Peter Beck ${ }^{2}$

\author{
Address: ${ }^{1}$ Ifakara Health Research and Development Centre (IHRDC), P. O. Box 53, Ifakara, Tanzania and ${ }^{2}$ Swiss Tropical Institute (STI), \\ Socinstrasse 57, 4002 Basel, Switzerland \\ Email: Kefas Mugittu* - kmugittu@ihrdc.or.tz; Blaise Genton - blaise.genton@hopsvd.ch; Hassan Mshinda - hmshinda@ihrdc.or.tz; \\ Hans Peter Beck - hans-peter.beck@unibas.ch \\ * Corresponding author
}

Published: 19 December 2006

Malaria Journal 2006, 5:126 doi:10.1 186/1475-2875-5-126
Received: 19 August 2006

Accepted: 19 December 2006

This article is available from: http://www.malariajournal.com/content/5/I//26

(C) 2006 Mugittu et al; licensee BioMed Central Ltd.

This is an Open Access article distributed under the terms of the Creative Commons Attribution License (http://creativecommons.org/licenses/by/2.0), which permits unrestricted use, distribution, and reproduction in any medium, provided the original work is properly cited.

\begin{abstract}
Artemisinin-based combination therapies (ACTs) are recommended for use against uncomplicated malaria in areas of multi-drug resistant malaria, such as sub-Saharan Africa. However, their longterm usefulness in these high transmission areas remains unclear. It has been suggested that documentation of the S769N PfATPase6 mutations may indicate an emergence of artemisinin resistance of Plasmodium falciparum in the field. The present study assessed PfATPase6 mutations (S769N and $\mathrm{A} 623 \mathrm{E})$ in 615 asymptomatic $P$. falciparum infections in Tanzania but no mutant genotype was detected. This observation suggests that resistance to artemisinin has not yet been selected in Tanzania, supporting the Ministry of Health's decision to adopt artemether+lumefantrine as first-line malaria treatment. The findings recommend further studies to assess PfATPase6 mutations in sentinel sites and verify their usefulness in monitoring emergency of ACT resistance.
\end{abstract}

\section{Background}

Resistance to antimalarials is a major drawback in effective malaria control in sub-Saharan Africa. Plasmodium falciparum has developed high levels of resistance to the cheap and safe chloroquine (CQ) and to sulfadoxinepyrimethamine (SP) $[1,2]$. Therefore, artemisinin-based combination therapy (ACT) is recommended for use in the whole of sub-Saharan Africa [3,4]. Fifteen out of 43 sub-Saharan African countries have already adopted artesunate + amodiaquine as first-line drug and the rest are at various stages of preparation for changes to the same regimen or to artemether + lumefantrine. Following increased SP resistance in Tanzania [5], the country has revised its malaria treatment policy to adopt artemether+lumefantrine. This change is supposed to be implemented over the whole country from December
2006. To date no relevant clinical resistance to artemisinins has been reported. However, the long-term usefulness of ACT in high transmission areas remains unclear [6]. Therefore, as ACT is becoming widely used in subSaharan Africa, the need for regular and comprehensive surveillance of resistance has been recognized. This should include in vitro and in vivo drug efficacy assays, pharmacokinetic analyses and the monitoring of molecular markers associated with resistance to the various components of ACTs.

Recently it was hypothesized, and later proved, that artemisinins interact [7] and selectively inhibit [8] PfATPase6, the only SERCA-type $\mathrm{Ca}^{2+}$-ATPase in the P. falciparum genome. A subsequent in vitro study in French Guyana showed that $P$. falciparum with elevated $I_{50}$ val- 
ues for artemisinins shared specific point mutations at codon $\mathrm{S} 769 \mathrm{~N}$ of the ATPase 6 locus. In addition, ATPase 6 A623E and E431K mutations were also associated with reduced $P$. falciparum susceptibility to artemisinins [9]. This study suggested that documentation of these mutations may indicate emergence of $P$. falciparum artemisinin resistance in the field. Therefore, the aim of this study was to assess and determine the baseline prevalence of ATPase 6 S769N and A623E mutations in Tanzania prior to adoption of ACT as first-line antimalarials drug.

\section{Methods}

The study was conducted from July to November 2003 and 2004 in the Ipinda (south-west), Mlimba (south-east) and Mkuranga (east) health facilities in Tanzania. Malaria transmission in these rural areas is perennial with peaks between May and July. The study assessed asymptomatic infections (by msp2 amplification) in 1,205 randomly selected individuals (601 in 2003 and 604 in 2004) living in proximity to the health facilities. P. falciparum DNA from 615 msp2 positive samples was amplified by polymerase chain reaction (PCR) using PfATPase6-specific primary and nested primer pairs. The nested reaction spun a 798bp fragment of the PfATPase6 gene from which single nucleotide polymorphisms (SNPs) at positions 623 and 769 were detected by DNA microarray technique and a subset of PCR products were sequenced for quality control. This DNA microarray technique is designed to simultaneously detect the 32 reported antimalarial resistance conferring SNPs in Pfdhfr, Pfdhps, Pfcrt Pfmdr1, and PfATPase6. A detailed account of this technique has been prepared to be published separately (Crameri et al, submitted). In this article, only the recently described PfATPase6 SNPs, which are thought to decrease parasite susceptibility to artemisinin, are reported. The study was approved by the Tanzanian national and institutional review boards.

\section{Results}

A total of 615 (51\%) out of 1,205 individuals were P. falciparum positive by msp2 PCR amplification. 485 (75.6\%) out of 615 had evaluable SNP data at positions $769(\mathrm{n}=$ $197)$ and $623(n=288)$ of the PfATPase6 gene. No ATPase6 $\mathrm{S} 769 \mathrm{~N}$ or A623E mutations were detected in any of the analyzed asymptomatic infection samples.

\section{Discussion}

The study detected neither S769N nor A623E PfATPase6 mutations in any of the three sites including Mkuranga, a coastal region close to urban Dar es Salaam where a high rate of uncontrolled use of artemisinin monotherapy was reported [10]. The findings suggest that resistance to artemisinin has not been selected yet in Tanzania and are consistent with the high ( 94\%) artemether + lumefantrine parasitological cure rates recorded in a multi-country efficacy trial including Tanzania's coastal region [11]. These observations support the Ministry of Health decision to adopt artemether + lumefantrine as first line treatment for uncomplicated malaria. However, it is still unclear whether artemisinin-based combinations in high transmission areas of sub-Saharan Africa will retain their usefulness or robustness as did artesunate + mefloquine in low transmission areas of south-east Asia [6].

The increase in $P$. falciparum multidrug resistance 1 (Pfmdr1) copy number is believed to reduce parasite sensitivity to some quinolines antimalarials $[12,13]$. Therefore, ATPase 6 genotype and Pfmdr1 copy number could make early warning signals for emergence of ACT resistance and enable investigators to timely advice the Ministries of Health on the most effective treatment strategies and appropriate policy-changing schedules. However, it should be noted that apart from one study [9], it has not been widely proven that SNPs in PfATPase6 confer resistance to artemisinins. Indeed one study [14] could not establish the function of ATPase 6 in the artemisinin resistance of Plasmodium chabaudi. Thus, the role of ATPase 6 in artemisinin resistance and its value in monitoring $P$. falciparum resistance to artemisinin remains to be confirmed.

\section{Conflicts of interests}

The author(s) declare that they have no competing interests.

\section{Authors' contributions}

K. Mugittu, B. Genton, H-P. Beck and H. Mshinda designed the study. K Mugittu performed molecular genotyping and data summarization. H. Mshinda supervised the field work in Tanzania. K. Mugittu wrote the article and all others contributed to it.

\section{Funding}

This study was funded jointly by the European Union (Grant no. QLK2-CT-2002-01503, BBW 03.0001) and the Swiss National Foundation for Science (Grant no. 3100067260). IHRDC receives core financial support from Swiss Agency for Development and Co-operation. Kefas Mugittu's PhD training programme is supported by Research Training Grants from the UNICEF/UNDP/World Bank/WHO Special Programme for Research and Training in Tropical Diseases (TDR).

\section{Acknowledgements}

We are grateful to the Tanzania Ministry of Health $(\mathrm{MoH})$, National Malaria Control Program (NMCP). We are thankful to the on-site clinical and field officers, nurses and parents/guardians who consented to participate and to Prof. M. Tanner for his critical comments on the manuscript.

\section{References}

I. The East African Network for Monitoring Antimalarial Treatment (EANMAT): The efficacy of antimalarial monotherapies, sulfadoxine-pyrimethamine and amodiaquine in East Africa: 
implication for sub-regional policy. Trop Med Int Health 2003, 8:860-867.

2. Talisuna AO, Bloland P, D'Alessandro U: History, dynamics, and public health importance of malaria parasite resistance. Clin Microbiol Rev 2004, 17:235-254.

3. World Health Organization 2006. Guidelines for malaria treatment [http://www.who.int/malaria/docs/ TreatmentGuidelines2006.pdf]

4. Arrow J, Panosian CB, Gelband H, (Eds): Saving lives, buying time: Economics of malaria drugs in an age of resistance Washington DC, USA: National Academy Press; 2004.

5. Mugittu K, Ndejembi M, Malisa A, Lemnge M, Premji Z, Mwita A, Nkya W, Kataraihya J, Abdulla S, Beck HP, Mshinda H: Therapeutic efficacy of sulfadoxine-pyrimethamine and prevalence of resistance markers in Tanzania prior to revision of malaria treatment policy: Plasmodium falciparum dihydrofolate reductase and dihydropteroate synthase mutations in monitoring in vivo resistance. Am J Trop Med Hyg 2004, 71 :696-702.

6. Duffy PE, Sibley $\mathrm{CH}$ : Are we losing artemisinin combination therapy already? Lancet 2005, 366: 1960-1963.

7. Eckstein-Ludwig U, Webb RJ, Van Goethem ID, East JM, Lee AG, Kimura M, O'Neill PM, Bray PG, Ward SA, Krishna S: Artemisinins target the SERCA of Plasmodium falciparum. Nature 2003 424:957-961.

8. Uhlemann AC, Cameron A, Eckstein-Ludwig U, Fischbarg J, Iserovich P, Zuniga FA, East M, Lee A, Brady L, Haynes RK, Krishna S: A single amino acid residue can determine the sensitivity of SERCAs to artemisinins. Nat Struct Mol Biol 2005, I 2:628-629.

9. Jambou R, Legrand E, Niang M, Khim N, Lim P, Volney B, Ekala MT, Bouchier C, Esterre P, Fandeur T, Mercereau-Puijalon OS: Resistance of Plasmodium falciparum field isolates to in-vitro artemether and point mutations of the SERCA-type PfATPase6. Lancet 2005, 366:1960-1963.

10. Kachur SP, Black C, Abdulla S, Goodman C: Putting the genie back in the bottle? Availability and presentation of oral artemisinin compounds at retail pharmacies in urban Dar-es-Salaam. Malar J 2006, 5:25.

II. Falade C, Makanga M, Premji Z, Ortmann CE, Stockmeyer M, de Palacios PI: Efficacy and safety of artemether-lumefantrine (Coartem) tablets (six-dose regimen) in African infants and children with acute, uncomplicated falciparum malaria. Trans R Soc Trop Med Hyg 2005, 99:459-467.

12. Price RN, Cassar C, Brockman A, Duraisingh M, van Vugt M, White $\mathrm{NJ}$, Nosten F, Krishna S: The pfmdrl gene is associated with a multidrug-resistant phenotype in Plasmodium falciparum from the western border of Thailand. Antimicrob Agents Chemother 1999, 43( ( 2):2943-9.

13. Duraisingh MT, Cowman AF: Contribution of the pfmdrl gene to antimalarial drug-resistance. Acta Trop 2005, 94(3): 18I-90.

14. Afonso A, Hunt P, Cheesman S, Alves AC, Cunha CV, do Rosario V, Cravo P: Malaria parasites can develop stable resistance to artemisinin but lack mutations in candidate genes atp6 (encoding the sarcoplasmic and endoplasmic reticulum Ca2+ ATPase), tctp, mdrl, and cgl 0. Antimicrob Agents Chemother 2006, 50:480-489.

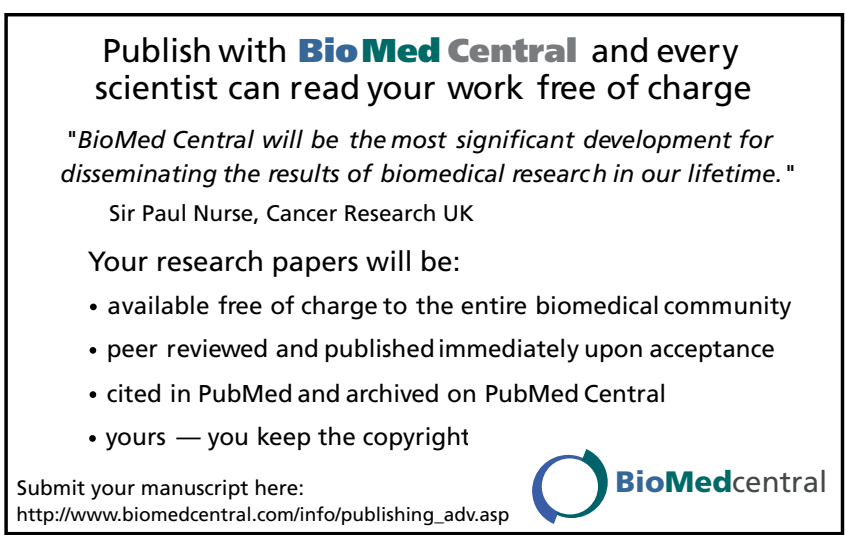

